\title{
Análisis exploratorio de prensa escrita de cuatro países latinoamericanos sobre violencia doméstica en contexto de confinamiento por COVID-19 desde un enfoque de género
}

\author{
Exploratory analysis of the written press of four Latin American \\ countries on domestic violence in the context of confinement due to \\ COVID-19 from a gender perspective
}

\author{
Ana Lucía Rodríguez-Gutiérrez ${ }^{1}$ \\ Esmeralda Cantón-Cruz ${ }^{2}$
}

\begin{abstract}
RESUMEN
Este artículo tuvo como objetivo principal analizar el abordaje dado a la violencia doméstica en el marco del Módulo de Psicología y Violencia Doméstica de la Universidad de Costa Rica (UCR), durante la pandemia provocada por el COVID-19; esto en las noticias de prensa escrita provenientes de medios virtuales en el contexto latinoamericano y en el período comprendido entre marzo a mayo del año 2020. La muestra estuvo conformada por 12 noticias y 8 notas de prensa provenientes de 4 países latinoamericanos y de 4 organizaciones gubernamentales y no gubernamentales, las cuales fueron escogidas bajo el criterio de saturación. Como principales resultados, se encontró que las noticias y notas de prensa visualizan la preocupación de las autoridades y organizaciones correspondientes ante el inminente aumento en casos de violencia doméstica y violencia de género, además, dejan en claro la necesidad de nuevos mecanismos de denuncias y la importancia de la sensibilización en temas de género al personal de las instituciones que atienden los casos de violencia.
\end{abstract}

Palabras clave: violencia doméstica, confinamiento, COVID-19, género, emergencia humanitaria.

\begin{abstract}
This article had the general objective of analyzing the approach to domestic violence in the framework of the Psychology and Domestic Violence Module of the University of Costa Rica (UCR), during the pandemic caused by COVID-19, in the written press news from virtual media in the Latin American context, in the period between March to May of the year 2020. The sample consisted of 12 news and 8 press releases, from 4 Latin American countries and 4 governmental and non-governmental organizations, which were chosen under the saturation criterion. As main results it was found that the news and press releases visualize the concern of the organizations that deal with cases of violence and the authorities about the imminent increase in cases of domestic violence and gender violence, also, they make clear the need for new complaint mechanisms and the importance of sensitizing gender issues to the staff of the institutions that deal with cases of violence.
\end{abstract}

Key Words: Domestic violence, confinement, COVID-19, gender, humanitarian emergency.

\footnotetext{
${ }^{1}$ Universidad de Costa Rica. Bachiller en Psicología y en Enseñanza de la Psicología. San José, Costa Rica. Correo electrónico: ana.rodriguezgutierrez@ucr.ac.cr ORCID: https://orcid.org/0000-0002-3636-9577

${ }^{2}$ Universidad de Costa Rica. Bachiller en Psicología y en Enseñanza de la Psicología. San José, Costa Rica. Correo electrónico: rubi.canton@ucr.ac.cr ORCID: https://orcid.org/0000-0002-9038-8533

DOI: 10.15517/WL.V16I2.47703

Recepción: 22/10/2021 Aceptación: 9/04/2021
} 


\section{Introducción}

La violencia doméstica puede ser entendida, en términos legales, en Costa Rica como una acción u omisión, directa o indirecta, ejercida contra un pariente por consanguinidad, afinidad o adopción hasta el tercer grado, inclusive, por vínculo jurídico o de hecho o por una relación de guarda, tutela o curatela y que produzca como consecuencia, el menoscabo de su integridad física, sexual, psicológica o patrimonial. El vínculo por afinidad subsistirá aun cuando haya finalizado la relación que lo originó3 . $^{2}$

De manera similar, Claramunt ${ }^{4}$ define la violencia intrafamiliar como toda acción $u$ omisión que tenga como resultado el daño a la integridad física, sexual, emocional o social de un ser humano, en el que debe mediar un vínculo familiar o íntimo entre la persona agresora y la persona agredida, mientras que la violencia doméstica se presenta característicamente en el seno del hogar. Hoy día, este tipo de violencia corresponde una problemática psicosocial ampliamente presente tanto a nivel internacional como nacional; la ONU Mujeres ${ }^{5}$ afirma que la violencia doméstica es, todavía en la actualidad, un problema generalizado a lo largo de todo el mundo, el cual se relaciona con la salud pública y se caracteriza por la violencia de género hacia las mujeres y niñas involucradas en el ámbito intrafamiliar.

Específicamente, en el caso de Latinoamérica, el Programa de las Naciones Unidas para el Desarrollo ${ }^{6}$ plantea que dicha región se ha caracterizado, con el paso del tiempo, por sus altos niveles de violencia doméstica, violencia doméstica cuyas manifestaciones incluyen abuso físico, psicológico, sexual y abandono dirigido hacia grupos sociales como menores de edad, personas adultas mayores y, principalmente, mujeres. Desde los años noventa, la violencia doméstica se ha considerado en América Latina y el Caribe un asunto de derechos humanos, un problema de salud pública y un serio obstáculo al desarrollo económico, debido a que muchas mujeres no tienen

\footnotetext{
${ }^{3}$ Ley No.7586 Contra la Violencia Doméstica (República de Costa Rica: Asamblea Legislativa de la República de Costa Rica, 1996), artículo.

${ }^{4}$ María Cecilia Claramunt, Casitas quebradas: El problema de la violencia doméstica en Costa Rica.(Costa Rica: Editorial Universidad Estatal a Distancia, 2006).

5 Organización de las Naciones Unidas-Mujeres, “Informe Anual 2018-2019”, https://www.unwomen.org//media/annual\%20report/attachments/sections/library/2019/un-women-annual-report-2018-2019es.pdf?la=es\&vs=5038 (consultada el 22 marzo 2020).

${ }^{6}$ Observatorio de violencia de género contra la mujeres y acceso a la justicia. "Femicidio", https://observatoriodegenero.poder-judicial.go.cr/soy-especialista-y-busco/estadisticas/femicidio/ (consultado el 22 marzo 2020).
} 
acceso a educación, salud o trabajos remunerados. Por lo tanto, este es un problema social necesario de cubrir en primer plano dentro de las agendas políticas de los gobiernos de la región ${ }^{7}$. Pese a esto, la introducción del tema en dichas agendas se logró gracias a los movimientos de mujeres, con la formulación de políticas sobre violencia doméstica en todos los países latinoamericanos ${ }^{8}$.

En enlace con la situación de pandemia por COVID-19, bajo la cual muchos países han adoptado la medida de cuarentena sanitaria para prevenir el contagio masivo del virus, Ailyn Torres $^{9}$ explica que el confinamiento ha agravado los altos índices de violencia de género que ya existían, donde para el 2018 las Naciones Unidas alertaban que 1 de cada 3 mujeres de la región asegura haber sufrido violencia física o sexual en una relación de pareja y un $77 \%$ de los crímenes sexuales ha ocurrido dentro de las viviendas. En México, específicamente, se anunció que la cifra de llamadas al 911 por violencia de género ha aumentado un 25\%; en Argentina durante los primeros 10 días de cuarentena hubo 11 femicidios y la línea de atención a casos de violencia de género se saturó. En el caso de Ecuador, para el día 3 de abril ya se registraban 500 denuncias de violencia contra las mujeres; en el $78 \%$ de los casos se otorgaron medidas de protección a las víctimas.

De igual modo, la autora señala que, en Bolivia, hasta el 15 de abril, se reportaron 33 casos de violación a menores de edad y más de 1200 mujeres fueron víctimas de violencia, entre las cuales hubo 4 femicidios. Además, las condiciones en las que viven grandes grupos de mujeres, como pobreza, poco acceso a la tecnología y situaciones de donde sus cuerpos e intereacciones, son controlados por sus padres, esposos, novios u otros actores sociales, dificultan el acceso a las redes de apoyo comunitarias para poder brindarles servicios.

Asimismo, la Organización de las Naciones Unidas-Mujeres ${ }^{10}$ identificó que durante el periodo de la pandemia del COVID-19, las mujeres califican como la población más afectada por

\footnotetext{
${ }^{7}$ Observatorio de violencia de género contra la mujeres y acceso a la justicia. "Violencia doméstica", https://observatoriodegenero.poder-judicial.go.cr/soy-especialista-y-busco/estadisticas/violencia-domestica/ (consultado el 22 marzo 2020).

${ }^{8}$ Observatorio de violencia de género contra la mujeres y acceso a la justicia. "Femicidio", https://observatoriodegenero.poder-judicial.go.cr/soy-especialista-y-busco/estadisticas/femicidio/ (consultado el 22 marzo 2020).

${ }^{9}$ Ailyn Torres, "La seguridad de las mujeres frente al Covid-19: Nudos críticos para América Latina". Fundación Friedrich Ebert, http://library.fes.de/pdf-files/bueros/la-seguridad/16137.pdf (consultado el 22 marzo 2020).

${ }^{10}$ Organización de las Naciones Unidas-Mujeres, "Prevención de la violencia contra las mujeres frente a COVID-19 en América Latina y el Caribe", Organización de las Naciones Unidas, https://lac.unwomen.org/es/digiteca/publicaciones/2020/04/prevencion-de-la-violencia-contra-las-mujeres-frente-acovid-19 (consultado el 25 marzo 2020)
} 
los riesgos de violencia Debido al aumento de las tensiones en el hogar; algunas de las dificultades son: aumento del aislamiento, impacto económico que podría generar barreras adicionales para acabar una relación de violencia y aumento del riesgo de explotación sexual. De igual modo, se ha comentado que la experiencia histórica de cuarentenas anteriores ha dejado como consecuencia la reducción de altos generadores de empleo femenino como el comercio o el turismo. En suma, se dan mayores costos físicos, emocionales y mayor riesgo de infección debido al cuidado de personas enfermas, niños y niñas, y el manejo de tareas del hogar.

Durante el contexto de la pandemia por COVID-19, distintos medios de comunicación han declarado un aumento de riesgo por el incremento de manifestaciones de violencia doméstica debido al confinamiento. En Costa Rica, el Observatorio de Violencia de Género contra la Mujeres y Acceso a la Justicia ${ }^{11}$ reveló que para el primer trimestre del año 2020 el número de casos entrados en Juzgados de Violencia Doméstica fue de un total de 14.513 (1770 casos más a comparación del mismo periodo en el año anterior), y clarifica que cualquier estadística generada en tiempo de confinamiento por la propagación del virus debe ser interpretada con mucha cautela, pues muchas mujeres al convivir con sus agresores pueden tener muchas más limitaciones para denunciar. El informe sobre los datos obtenidos durante el 2019 con respecto a los femicidios, registra que, en total, 9 mujeres murieron a causa de violencia de género. Para el año 2020, los datos aún se encuentran incompletos ya que varias de las muertes de mujeres se encuentran aún en investigación.

Por ende, es posible visualizar que la violencia doméstica corresponde un serio problema en torno a la salud pública en los países latinoamericanos en estudio. Desde la literatura, Claramunt argumenta que este tipo de violencia, en particular, radica en la existencia de un contacto íntimo entre la persona agresora y la persona víctima de agresión, esto quiere decir que abarca la violencia sucedida en grupos que satisfagan, para sus integrantes, las necesidades afectivas, de protección y de cuidado que tradicionalmente son responsabilidad de la familia. Asimismo, se destaca que la violencia intrafamiliar constituye un problema de salud pública, un obstáculo para el desarrollo socioeconómico y una barrera en el ejercicio pleno de los derechos humanos de las mujeres ${ }^{12}$.

\footnotetext{
${ }^{11}$ Observatorio de violencia de género contra la mujeres y acceso a la justicia. "Femicidio", https://observatoriodegenero.poder-judicial.go.cr/soy-especialista-y-busco/estadisticas/femicidio/ (consultado el 22 marzo 2020).

${ }^{12}$ María Cecilia Claramunt, Casitas quebradas: El problema de la violencia doméstica en Costa Rica.(Costa Rica: Editorial Universidad Estatal a Distancia, 2006).
} 
Específicamente, en lo que respecta a la salud, la autora menciona que la violencia doméstica es una de las principales causas de discapacidad y muerte entre mujeres, pues provoca serias afecciones físicas, entre ellas hematomas, fracturas, enfermedades de transmisión sexual, abortos, estrés crónico, hipertensión, diabetes, asma y obesidad. Además, se menciona que las mujeres que viven en situaciones de violencia doméstica suelen tener una muy baja autoestima, la cual afecta directamente su comportamiento, productividad en el trabajo, capacidad para protegerse, buscar ayuda y denunciar su caso.

\subsection{Algunos antecedentes sobre situaciones de crisis y emergencia y violencia doméstica}

La importancia de la relación entre violencia doméstica y confinamiento ha sido advertida en situaciones de epidemia por diversas fuentes. La Unidad de Salud Mental y Uso de Sustancias y la Organización Panamericana de la Salud ${ }^{13}$ mencionan en el trabajo titulado Protección de la salud mental y atención psicosocial en situaciones de epidemias que, dentro de las manifestaciones psicosociales, en la fase durante la epidemia, se puede advertir un incremento de conductas violentas de la mano con un consumo excesivo de alcohol. Asimismo, se plantea que durante la fase posterior a la epidemia, deben considerarse las consecuencias sociales y de salud mental, incluyendo aquellas inducidas por violencia.

En la misma línea, Harman ${ }^{14}$ menciona que en epidemias como la del Ébola se ha evidenciado la invisibilización que sufren las mujeres y la falta de enfoque de género en la atención y la gobernanza mundial de la salud, lo cual resulta más preocupante en un contexto de

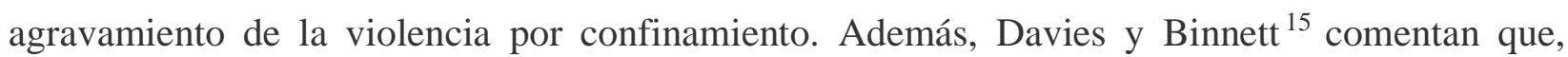
durante los periodos de crisis sanitarias, la provisión de salud se enfoca en las problemáticas inmediatas, dejando de lado el garantizar los derechos que más afectan a la población femenina,

\footnotetext{
${ }^{13}$ Unidad de Salud Mental y Uso de Sustancias y la Organización Panamericana de la Salud, "Protección de la salud mental y atención psicosocial en situaciones de epidemias", https://www.paho.org/disasters/index.php?option=com_docman\&view=download\&category_slug=informes-

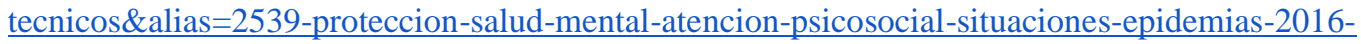

539\&Itemid=1179\&lang=e

${ }^{14}$ Sophie Harman, "Ebola, gender and conspicuously invisible women in global health governance", Third World Quarterly, (2016): 524-541.

${ }^{15}$ Sara Davies y Belinda Bennett, "A Gendered Human Rights Analysis Of Ebola And Zika: Locating Gender In Global Health Emergencies". International Affairs, 2016, https://doi.org/10.1111/1468-2346.12704 (consultado el 27marzo 2020).
} 
por ejemplo, la salud reproductiva y sexual y la garantía de seguridad. Conjuntamente, se evidencia un aumento de riesgo de sufrir violencia doméstica, violencia física contra sus cuerpos y embarazos no deseados.

Del mismo modo, se presenta que, en el caso de países que han sufrido de emergencias humanitarias, las mujeres se encuentran en una posición altamente vulnerable en temas de acceso a la economía, salud y nutrición, asimismo, se evidencia que la inseguridad ciudadana es aún más severa hacia la mujer, pues hay un incremento en los números de muertes violentas hacia ellas.

En el caso específico de Venezuela, las mujeres enfrentan numerosos retos en el disfrute pleno de sus derechos más elementales, entre ellos, el derecho a vivir una vida libre de violencia. Al ser víctimas de violencia estructural, se genera un incremento en el número de femicidios (a pesar de no tener cifras oficiales) y una implementación carente de políticas de políticas de prevención, sanción y eliminación de la violencia hacia las mujeres 16.

En el caso de Haití, tras el terremoto sufrido en el año 2010 y el Huracán Sandy en el 2012, se presenta una fuerte emergencia humanitaria, en la cual se ha visto presente la violencia contra las mujeres y menores de edad, esto relacionado a una violencia histórica y estructural arraigada a la cultura y a la idea de «lo que pasa en el hogar se queda en el hogar». Asimismo, ha esto se une que los gobiernos enfocan su atención en otras áreas de la crisis, por lo que los apoyos sociales hacia la mujer son deficientes. ${ }^{17}$

Algunos otros países que se pueden mencionar en situación de emergencia humanitaria son Siria y Yemen, donde la violencia política ha transformado la región en un espacio altamente peligroso para las mujeres, donde el $58 \%$ de las mujeres víctimas de homicidio en 2017 fueron asesinadas por su pareja o por miembros de su familia. De igual forma, la mayoría de los asesinatos han sido hacia mujeres, consecuencia de creencias misóginas, desigualdad y la dependencia económica, principalmente, que persisten, en su mayoría, los países de bajos ingresos. 18

\footnotetext{
${ }^{16}$ Asociación Venezolana para una Educación Sexual Alternativa (AVESA), "Mujeres al Límite, el peso de la emergencia humanitaria: vulneración de los derechos humanos de las mujeres en Venezuela". 2017, https://clacaidigital.info/bitstream/handle/123456789/1109/Mujeres\%20al\%20limite.pdf?sequence=5\&isAllowed=y ${ }^{17}$ United Nation Secretary-General's Campaign, "UNIFEM Haití: Apoyar la capacidad nacional en la violencia de género es una tarea impostergable", https://www.cepal.org/mujer/noticias/noticias/5/41145/UNIFEM Haiti Apoyar.pdf

${ }^{18}$ Organización de las Naciones Unidas-Mujeres. 2019. Informe Anual 2018-2019, (2019). https://www.unwomen.org/-/media/annual\%20report/attachments/sections/library/2019/un-women-annual-report2018-2019-es.pdf?la=es\&vs=5038
} 
La investigación nacional sobre la relación entre violencia doméstica y confinamiento es escasa, no obstante, investigaciones en temática de género, como la de Sandra Pereira 19, contribuyen a reforzar la urgencia de atender los casos de violencia doméstica para aumentar el beneficio a la salud de las mujeres. La autora argumenta que la población femenina tienen una forma particular de enfermar que se relaciona con la socialización en un entorno patriarcal que ha establecido una forma específica de ser y pensarse mujer y de ser percibida como mujer en la sociedad. Adicionalmente, menciona que la violencia doméstica es una de las formas de violencia masculina más graves hacia la mujer, ya que, como se ha visto en los periodos de emergencias sanitarias y humanitarias, se ejerce en el núcleo familiar y en una relación afectiva y de confianza, bajo el mito de la privacidad y la prohibición del Estado a entrar en ese ámbito privado.

Por su parte, Adriana Rodríguez ${ }^{20}$ plantea en su artículo que, en tiempos de pandemia, la mujer ha estado expuesta a un aumento en la carga de trabajo doméstico no remunerado por el contexto de confinamiento, cuya situación guarda una estrecha relación con las diferencias de género, el sexismo y machismo ya acusados por el feminismo desde tiempo atrás. Para la autora, este malestar suscitado del sistema patriarcal hegemónico exacerba el control social sobre las mujeres y las fuerzas que mantienen su opresión, atentando directamente contra la igualdad y el bienestar generalizado.

\subsection{Aportes iniciales para la comprensión de la relación entre violencia y confinamiento por la pandemia de COVID-19}

La Alianza para la protección de la niñez y adolescencia en la acción humanitaria ${ }^{21}$ plantea en el trabajo titulado Protección de la niñez y adolescencia durante la pandemia del coronavirus que la situación social por el COVID-19 se ha caracterizado por alteraciones en la rutina diaria, lo

\footnotetext{
${ }^{19}$ Sandra Pereira. Violencia contra las mujeres en la relación de pareja: Diagnóstico realizado en el Juzgado Contra la Violencia Doméstica de Cartago para un Abordaje integral en el Poder Judicial de la Violencia Intrafamiliar desde la perspectiva de Género. (Tesis de Maestría Profesional en Violencia Intrafamiliar y de Género, Universidad de Costa Rica, 2018).

${ }^{20}$ Adriana Rodríguez, "El tiempo de las mujeres: trabajo y malestar femenino en tiempos de pandemia. Reflexiones", Reflexiones, (2020): 1-10.

${ }^{21}$ Alianza para la protección de la niñez y adolescencia en la acción humanitaria, "Protección de la niñez y adolescencia durante la pandemia del coronavirus", (2020), https://www.unicef.org/costarica/media/2191/file/Nota\%20t\%C3\%A9cnica:\%20Protecci\%C3\%B3n\%20de\%20la\%2 0ni\%C3\%B1ez\%20y\%20adolescencia\%20durante\%201a\%20pandemia\%20del\%20coronavirus\%20.pdf (consultado el 29 marzo 2020): 4-6.
} 
cual genera inestabilidad en la familia y en otras áreas de vida. Las medidas promovidas para prevenir y controlar la transmisión del COVID-19, entre ellas la cuarentena y el aislamiento en el hogar, no han tomado en cuenta aspectos de género y dejan de lado el riesgo que implica el aumento de la vulnerabilidad a la violencia y el malestar psicosocial en niños, niñas y adolescentes. Dentro del informe, se presenta un modelo sobre el impacto socioecológico del COVID-19, que incluye, entre diversos factores, mayor riesgo de violencia en los miembros de la familia convivientes en el hogar y más probabilidades de sufrir maltrato, descuido, violencia, explotación y estrés psicosocial infantil. Los principales riesgos potenciales que se plantean, en correspondencia a la temática de violencia doméstica, se dirigen hacia el riesgo por maltrato físico y emocional que incluye situaciones como "supervisión disminuida y trato negligente a niños, niñas y adolescentes... aumento del abuso infantil y la violencia doméstica o interpersonal... envenenamiento y otros peligros y riesgos de lesión para los niños y niñas... acceso limitado o inexistente a los servicios de protección de la niñez y adolescencia”, y el riesgo por violencia de género, que puede manifestarse por un "aumento del riesgo de explotación sexual de los niños y las niñas, incluido el sexo como moneda de cambio, la explotación infantil con fines comerciales y el matrimonio precoz forzado e infantil", así como un "acceso limitado o inexistente a los servicios de protección de la niñez y adolescencia contra la violencia de género".

Sobre la situación de la violencia doméstica y la pandemia del COVID-19, Bradbury-Jones y Isham $^{22}$ sugieren que el cambio en la rutina ha provocado un aumento en el estrés físico y psicológico en las personas, lo cual puede aumentar el riesgo de que se presente violencia doméstica, condición en que las mujeres, los niños y niñas son la población más vulnerable ante la crisis, principalmente, porque son una población que ya se encontraba en relaciones abusivas o violentas previo al inicio del confinamiento. En la misma línea, se menciona que en países como Brasil se ha registrado un aumento de al menos un $10 \%$ en los reportes de casos de violencia doméstica.

Es importante mencionar que el miedo y la incertidumbre asociados con las pandemias provee de un ambiente que puede exacerbar o provocar diversas formas de violencia, por lo cual, mantener un contacto social en medio del distanciamiento físico es de suma importancia para

\footnotetext{
${ }^{22}$ Caroline Bradbury-Jones y Louise Isham, "The pandemic paradox: The consequences of COVID-19 on domestic $\begin{array}{lllll}\text { violence", } & \text { Journal } & \text { Clinical } & \text { Nursing, } & \text { (2020): }\end{array}$ 2049. https://onlinelibrary.wiley.com/doi/epdf/10.1111/jocn.15296
} 
reportar los casos de abuso, así como para monitorear el bienestar de aquellas personas que se sospecha, puedan estar en riesgo de violencia. Se evidencia también, la necesidad de que el personal de salud y salud mental se encuentren en total disposición de realizar escucha activa y empática ${ }^{23}$.

Por su parte, el estudio realizado por Andrew Campbell ${ }^{24}$ señala que existe un riesgo igual de grave entre contagiarse del virus del COVID-19 y mantenerse en confinamiento con un perpetrador de violencia doméstica. Se explica que las personas que son victimarias de este tipo de violencia suelen aislar a sus víctimas como forma de control para reducir las posibilidades de escapatoria, y el confinamiento social, evidentemente, propicia estas conductas. En suma, el estrés asociado a factores de riesgo de violencia doméstica, tales como los recursos económicos limitados, el desempleo y una limitada red de apoyo, podría incrementarse durante dicho periodo, lo cual incrementa el riesgo de violencia o femicidios. Por lo tanto, es importante que se creen estrategias de colaboración comunitaria que permitan que las personas que están en riesgo o sufren violencia, puedan tener recursos para comunicar de manera segura lo que están viviendo.

Dado lo anterior, y ante la reciente importancia investigativa de la problemática sobre violencia en tiempos de confinamiento por el COVID-19, el presente estudio corresponde a un acercamiento al tema de manera exploratoria. Debido al papel fundamental que los medios de comunicación tienen en momentos de crisis humanitarias y en virtud de los niveles de información y educación que proporcionan a la población, se retoma la importancia de indagar el posicionamiento que la violencia doméstica presenta en el abordaje mediático. Por tanto, la pregunta de investigación va dirigida hacia cuál es el contenido de las noticias y notas de prensa relacionadas con violencia doméstica y confinamiento por COVID-19, proponiendo analizar desde un enfoque de género su abordaje y los mensajes sociales implícitos.

\footnotetext{
${ }^{23}$ Kim Usher, Navjot Bhullar, Joanne Durkin, Naomi Gyamfi y Debra Jackson, "Family violence and COVID-19: Increased vulnerability and reduced options for support", International Journal of Mental Health Nursing, (2020), https://onlinelibrary.wiley.com/doi/epdf/10.1111/inm.12735

${ }^{24}$ Andrew Campbell, "An increasing risk of family violence during the Covid-19 pandemic: Strengthening community collaborations to save lives. Forensic Science International: Reports, 2" (2020), 1-3. https://www.ncbi.nlm.nih.gov/pmc/articles/PMC7152912/
} 


\section{बrinum}

Wimblu, Rev. Estud. de Psicología UCR, 16(2) 2021 (Julio-Diciembre): 35-65 /ISSN: 1659-2107

\section{Metodología}

El presente estudio surge a raíz de la práctica profesionalizante del Módulo de Psicología y Violencia Doméstica de la carrera de Psicología (nivel de licenciatura) de la Universidad de Costa Rica (UCR). La investigación corresponde a un estudio cualitativo de alcance exploratorio, cuyo objeto de análisis es el abordaje de la violencia doméstica en noticias y notas de prensa escrita publicadas en medios virtuales a nivel nacional y latinoamericano, esto durante el periodo inicial de la pandemia por COVID-19 en el tiempo comprendido entre marzo-mayo del año 2020.

Para la depuración de los datos recopilados como muestra investigativa se volvió necesario filtrar la información tomando en cuenta que quienes escriben son intérpretes que analizan diferentes aspectos de una realidad o fenómeno. Dichos sujetos forman una opinión propia y promueven objetivos como informar, formar o entretener.25

De igual modo, fue necesario tomar en cuenta que 26 existen modos específicos de construir la información sobre la violencia o crímenes, los cuales responden al funcionamiento de las empresas informativas y al desarrollo del ejercicio periodístico. Es por eso que existen múltiples géneros y estrategias discursivas y, en consecuencia, se logra el llamado "contrato de lectura" donde los medios proponen a los lectores y estos construyen una narrativa interna o estructura particular de leer los delitos desde sus simbolismos y significantes. En esa línea, entonces, el mensaje se relaciona con la intención de comunicar y, a su vez, producir una respuesta. Dicha resolución estará ligada al ejercicio de percepción e interpretación de la persona a quien se dirige y estrechamente ligado a su historia particular, su cultura y circunstancias ${ }^{27}$.

Además, cabe destacar que en el periodismo escrito y, principalmente, difundido a través de redes sociales y medios virtuales, se busca una redacción de titulares orientada a llamar la atención de los lectores. No obstante, con el fin de lograr un periodismo viral, se difunden hechos

\footnotetext{
${ }^{25}$ Miguel Ángel Biasutto, "Noticia y mensaje: lectura e interpretación en los medios", COMUNICAR, 4, (1996): 2936. https://www.revistacomunicar.com/ojs/index.php/comunicar/article/view/C04-1995-06

${ }^{26}$ German Rey, Stella Martini, Amparo María, Marroquín Parducci, Xavier Altamirano Molina, Sergio Roncallo Dow, Claudia Wondratschke y Alberto Betancourt Posada, "Los relatos periodísticos del crimen", Centro de Competencia en Comunicación para América Latina, (2007), https://library.fes.de/pdf-files/bueros/c3comunicacion/07327.pdf

${ }^{27}$ Miguel Ángel Biasutto, "Noticia y mensaje: lectura e interpretación en los medios", COMUNICAR, 4, (1996): 2936. https://www.revistacomunicar.com/ojs/index.php/comunicar/article/view/C04-1995-06
} 
desinformados ya que las personas suelen compartir un titular llamativo incluso sin haber leído el contenido del cuerpo de la noticia. ${ }^{28}$

El objetivo general de la presente aproximación investigativa es analizar el abordaje de la violencia doméstica durante la pandemia provocada por el COVID-19 en las noticias de prensa escrita provenientes de medios virtuales a nivel nacional y latinoamericano, en el período comprendido entre marzo a mayo del año 2020. Para ello, se pretende abarcar los siguientes objetivos específicos:

1. Caracterizar las noticias y notas de prensa relacionadas con violencia doméstica y confinamiento por COVID-19 en el periodo comprendido entre marzo a mayo del año 2020 en el contexto latinoamericano.

2. Analizar el contenido de las noticias y notas de prensa relacionadas con violencia doméstica y confinamiento por COVID-19 y los mensajes sociales desde un enfoque de género.

\subsection{Muestra}

Se recopilaron un total de 12 noticias y 8 notas de prensa escrita publicadas en medios virtuales $(n=20)$. Se seleccionaron aquellas cuyo contenido vinculara el fenómeno de violencia doméstica con la situación de pandemia provocada por el COVID-19. Para ello, se estableció como criterio de inclusión a la prensa escrita latinoamericana publicada en el lapso de tiempo comprendido entre marzo-mayo del año 2020. Cabe destacar, además, que la recopilación de las noticias se realizó mediante el criterio de saturación.

\subsection{Procedimiento y método}

Se llevó a cabo una búsqueda en medios virtuales, noticias o notas de prensa que reflejaran la situación actual de la violencia doméstica en el contexto latinoamericano por la situación de confinamiento generada a raíz de la cuarentena. Para ello, se emplearon las palabras clave de búsqueda "violencia", “doméstico(a)", “confinamiento", “cuarentena”, "COVID-19”, "coronavirus", "mujeres", "menores de edad".

\footnotetext{
${ }^{28}$ Ángel Bazaco, Marta Redondo, Pilar Sánchez-García, "El clickbait como estrategia del periodismo viral: concepto y metodología". Revista Latina de Comunicación Social, (2019): 94-115. http://www.revistalatinacs.org/074paper/1323/RLCS-paper1323.pdf
} 
Wimblu, Rev. Estud. de Psicología UCR, 16(2) 2021 (Julio-Diciembre): 35-65 /ISSN: 1659-2107

Posterior a la recopilación de informativa, la presente aproximación se llevó a cabo mediante dos fases principales. En primer lugar, una caracterización hemerográfica de las noticias/notas de prensa recopiladas, con base a su titular, tipología de prensa escrita (noticia o nota de prensa), fecha de publicación, país de procedencia y principales temáticas abordadas. En una segunda fase, se realizó un análisis de contenido de las noticias/notas de prensa seleccionadas, contemplado en dos momentos. En un primer momento, dicho análisis fue dirigido a la sistematización de categorías que englobaran, de forma general, los principales planteamientos encontrados acerca de la situación de violencia doméstica y confinamiento por COVID-19. En un segundo momento, se realizó un análisis acerca de los principales mensajes sociales presentes en la prensa escrita seleccionada, desde un enfoque de género.

\section{Caracterización hemerográfica}

\subsection{Tabla 1. Ficha hemerográfica de las noticias y notas de prensa virtuales sobre violencia doméstica y situación por covid-19 recopiladas en el lapso comprendido entre marzo-mayo del año 2020}

\begin{tabular}{|c|c|c|c|c|}
\hline Titular & $\begin{array}{l}\text { Tipología } \\
\text { de prensa } \\
\text { escrita }\end{array}$ & $\begin{array}{c}\text { Fecha de } \\
\text { publicación }\end{array}$ & $\begin{array}{c}\text { País de } \\
\text { procedencia }\end{array}$ & Temáticas abordadas \\
\hline $\begin{array}{l}\text { INAMU prevé aumento en } \\
\text { violencia doméstica por } \\
\text { estrés relacionado a } \\
\text { COVID-19 }\end{array}$ & Noticia & $16 / 03 / 2020$ & Costa Rica & $\begin{array}{l}\text { Violencia doméstica, violencia contra la } \\
\text { mujer, emergencias humanitarias, } \\
\text { violencia de género }\end{array}$ \\
\hline $\begin{array}{l}\text { ¿Aumentaron los casos de } \\
\text { violencia doméstica con el } \\
\text { aislamiento social? }\end{array}$ & Noticia & $26 / 03 / 2020$ & Costa Rica & $\begin{array}{l}\text { Agresiones intrafamiliares, suicidio, } \\
\text { llamadas de atención de emergencias por } \\
\text { violencia de género. }\end{array}$ \\
\hline $\begin{array}{l}\text { El coronavirus golpea tres } \\
\text { veces a las mujeres: por la } \\
\text { salud, por la violencia } \\
\text { doméstica y por cuidar de } \\
\text { los otros }\end{array}$ & Noticia & $27 / 03 / 2020$ & ONU & $\begin{array}{l}\text { Carga laboral, violencia doméstica, } \\
\text { aislamiento, abuso, feminicidios, rol } \\
\text { cuidador, vulnerabilidad. }\end{array}$ \\
\hline $\begin{array}{l}\text { En tiempos de Covid-19 la } \\
\text { violencia de género no } \\
\text { entra en cuarentena }\end{array}$ & Noticia & $12 / 04 / 2020$ & Argentina & $\begin{array}{l}\text { Femicidios, victimario, femicidas dentro } \\
\text { del círculo de confianza, violencia hacia } \\
\text { las mujeres, denuncias, violencia de } \\
\text { género, crisis económica, crisis social, } \\
\text { crisis sanitaria, trabajadoras precarizadas, } \\
\text { traslado de víctimas. }\end{array}$ \\
\hline
\end{tabular}


Wimblu, Rev. Estud. de Psicología UCR, 16(2) 2021 (Julio-Diciembre): 35-65 /ISSN: 1659-2107

Mujeres, repercusiones del Noticia 18/04/2020 Costa Rica Violencia doméstica, disminución en confinamiento a raíz del llamadas de emergencia por violencia de coronavirus y violencia género, palabras claves para denunciar, doméstica situación de violencia doméstica en Europa, aislamiento.

\begin{tabular}{lllll}
\hline $\begin{array}{l}\text { ¿Cuál es la otra pandemia } \\
\text { que el Covid-19 ha } \\
\text { dejado en las sombras? }\end{array}$ & $19 / 04 / 2020$ & Nicaragua & $\begin{array}{l}\text { Violencia, redes de comunicación con } \\
\text { mujeres, violencia doméstica, peligro en } \\
\text { casa, violencia sexual, agresor, entornos } \\
\text { peligrosos. }\end{array}$ \\
\hline $\begin{array}{l}\text { Van al menos } 180 \\
\text { detenidos por violencia } \\
\text { doméstica }\end{array}$ & $19 / 04 / 2020$ & Argentina & $\begin{array}{l}\text { Encierro, violencia familiar, delitos de } \\
\text { secuestro. }\end{array}$ \\
$\begin{array}{l}\text { confinamiento social en } \\
\text { Argentina }\end{array}$ & & & \\
\end{tabular}

\begin{tabular}{llll}
\hline Femicidios durante Noticia & $19 / 04 / 2020$ & Panamá & $\begin{array}{l}\text { Mujer degollada, mujer asesinada, impacto } \\
\text { de tres femicidios, violencia doméstica }\end{array}$ \\
cuarentena por pandemia & & contra las mujeres, incremento en el riesgo \\
impactan en Panamá, & de violencia por aislamiento, \\
Defensoría del Pueblo & confinamiento, muertes violentas de \\
& mujeres.
\end{tabular}

OMS enfatiza en que la Noticia 19/04/2020 Costa Rica Alcohol, vulnerabilidad de salud, salud venta de licor debe mental, violencia. restringirse en medio de la pandemia

\begin{tabular}{|c|c|c|c|c|}
\hline $\begin{array}{l}\text { Violencia doméstica, la } \\
\text { otra urgencia de América } \\
\text { Latina en cuarentena }\end{array}$ & Noticia & $20 / 04 / 2020$ & Costa Rica & $\begin{array}{l}\text { Violencia doméstica, agresor, limitaciones } \\
\text { para acceder a la justicia, homicidios } \\
\text { dolosos, abusos, proteger a la mujer, } \\
\text { víctimas. }\end{array}$ \\
\hline $\begin{array}{l}\text { Confinamiento por } \\
\text { coronavirus sube el riesgo } \\
\text { de violencia intrafamiliar }\end{array}$ & Noticia & $20 / 04 / 2020$ & Costa Rica & $\begin{array}{l}\text { Violencia doméstica, agresores, } \\
\text { aislamiento social, personas que maltratan, } \\
\text { incertidumbre y ansiedad. }\end{array}$ \\
\hline $\begin{array}{lcr}\text { Millones } & \text { de } & \text { mujeres } \\
\text { sufrirán } & \text { embarazos no } \\
\text { deseados } & \text { durante la } \\
\text { pandemia de coronavirus }\end{array}$ & Noticia & $28 / 04 / 2020$ & Costa Rica & $\begin{array}{l}\text { Acceso a anticonceptivos, abuso, retrasos } \\
\text { en erradicar la mutilación femenina, } \\
\text { maltrato infantil, violencia de género. }\end{array}$ \\
\hline $\begin{array}{l}\text { La otra pandemia: } \\
\text { violencia en el hogar en } \\
\text { tiempos de cuarentena }\end{array}$ & $\begin{array}{l}\text { Nota de } \\
\text { prensa }\end{array}$ & $12 / 04 / 2020$ & PNUD Perú & $\begin{array}{l}\text { Violencia doméstica, aislamiento, } \\
\text { feminicidios, riesgo de violencia contra } \\
\text { mujeres y niñas, sensibilización para } \\
\text { prevenir la violencia y promover la } \\
\text { igualdad. }\end{array}$ \\
\hline
\end{tabular}


Wimblu, Rev. Estud. de Psicología UCR, 16(2) 2021 (Julio-Diciembre): 35-65 /ISSN: 1659-2107

Violencia contra las Nota de 19/04/2020 ONU mujeres: la pandemia en la prensa sombra
Violencia doméstica, derechos humanos, búsqueda de ayuda por parte de mujeres, diversas formas de discriminación.

\begin{tabular}{|c|c|c|c|c|}
\hline $\begin{array}{l}\text { Nota técnica: Protección de } \\
\text { la niñez y adolescencia } \\
\text { durante la pandemia del } \\
\text { coronavirus }\end{array}$ & $\begin{array}{l}\text { Nota de } \\
\text { prensa }\end{array}$ & $19 / 04 / 2020$ & UNICEF & $\begin{array}{l}\text { Cambios en la rutina, riesgo de protección } \\
\text { a la niñez y adolescencia. }\end{array}$ \\
\hline $\begin{array}{l}\text { COVID-19: Ante el } \\
\text { endurecimiento de las } \\
\text { medidas de contención, } \\
\text { aumenta el riesgo de que } \\
\text { los niños sufran abusos, } \\
\text { abandono, explotación y } \\
\text { violencia, dice UNICEF }\end{array}$ & $\begin{array}{l}\text { Nota de } \\
\text { prensa }\end{array}$ & $20 / 04 / 2020$ & UNICEF & $\begin{array}{l}\text { Amenazas, niños y niñas, garantizar } \\
\text { seguridad y bienestar, vulnerabilidad, } \\
\text { violencia doméstica contra mujeres, niñas } \\
\text { y niños, centros de atención. }\end{array}$ \\
\hline $\begin{array}{l}\text { INAMU y Naciones } \\
\text { Unidas reúnen esfuerzos } \\
\text { para apoyar a mujeres en } \\
\text { riesgo de violencia }\end{array}$ & $\begin{array}{l}\text { Nota de } \\
\text { prensa }\end{array}$ & $08 / 05 / 2020$ & INAMU & $\begin{array}{l}\text { Vida libre de violencia, campaña contra la } \\
\text { violencia de género, servicios que presta el } \\
\text { INAMU, líneas de atención telefónicas, } \\
\text { atención de la violencia. }\end{array}$ \\
\hline $\begin{array}{l}\text { Prevención de la violencia } \\
\text { contra las mujeres frente a } \\
\text { COVID-19 en América } \\
\text { Latina y el Caribe }\end{array}$ & $\begin{array}{l}\text { Nota de } \\
\text { prensa }\end{array}$ & $16 / 05 / 2020$ & ONU & $\begin{array}{l}\text { Violación de los derechos humanos, } \\
\text { feminicidios, femicidios, violencia contra } \\
\text { las mujeres y niñas, prevención de la } \\
\text { violencia contra las mujeres y niñas. }\end{array}$ \\
\hline
\end{tabular}

Las mujeres en el centro de Nota de 16/05/2020 ONU

las iniciativas de prensa recuperación del COVID-

19

Derechos de las mujeres, pobreza, redes de protección social, violencia contra las mujeres, maltratadores, medidas de protección para mujeres, igualdad de género.

Igualdad de género en Nota de 16/05/2020 ONU tiempos del COVID-19 prensa

Salud sexual, salud reproductiva, necesidades psicosociales, violencia de pareja, violencia doméstica, medidas de protección social, mujeres en la toma de decisiones.

\footnotetext{
Fuente: Elaboración propia.
}

\subsection{Reseña hemerográfica}

En total, la muestra estuvo conformada por 12 noticias y 8 notas de prensa, provenientes de 4 países latinoamericanos y de 4 organizaciones gubernamentales y no gubernamentales. Ampliando este punto, se encontraron 4 (20\%) notas de prensa provenientes de la ONU, 2 (10\%) notas de prensa de UNICEF, 1 (5\%) nota de prensa del INAMU (Costa Rica) y 1 (5\%) nota de prensa de PNUD Perú. En el caso de las noticias, se encontraron 7 (35\%) noticias de Costa Rica, 1 
(5\%) noticia de la ONU, 1 (5\%) noticias de Panamá, 2 (10\%) noticias de Argentina, y 1 (5\%) noticia de Nicaragua.

Con respecto a las temáticas que fueron abordadas con mayor frecuencia dentro de las noticias y notas de prensa, se encontraron los siguientes resultados: violencia doméstica (Mo:11), aislamiento (Mo:4), violencia de género (Mo:3), abusos (Mo:3), femicidios (Mo:3), violencia contra las mujeres (Mo:3), rol cuidador (Mo:3); las otras temáticas que fueron encontradas se presentaron en una frecuencia igual o menor que $2^{29}$.

\section{Resultados: análisis de contenido}

\subsection{Principales categorías de información sobre la situación de violencia doméstica y confinamiento por COVID-19 en las noticias y notas de prensa analizadas}

4.1.1 Incremento de la violencia doméstica durante el contexto de confinamiento por COVID19

Dentro del material mediático analizado, en el contexto de la crisis sanitaria mundial provocada por el SAR COV 2, se encuentra como principal mecanismo para evitar la propagación del virus que causa el COVID-19 el distanciamiento social y el confinamiento en los hogares. Esto, en inicio, se presenta como la medida para resguardar la vida de una gran cantidad de personas en el planeta, sin embargo, tiene como daño colateral un posible incremento en el número de casos de violencia doméstica y casos de femicidios. ${ }^{30} 3132$

Si bien los casos de violencia contra la mujer ya estaban presentes en muchas viviendas de Latinoamérica y el mundo, la situación de convivencia constante en el hogar durante el período de confinamiento con la persona agresora puede ser un detonante de nuevos casos de violencia

\footnotetext{
${ }^{29}$ Se observó que los referentes de búsqueda excluyeron noticias/notas de prensa acerca de sucesos específicos, por lo cual no hubo unidades de análisis de dicho tipo de prensa escrita en este estudio.

${ }^{30}$ Semanario Universidad, "Violencia doméstica, la otra urgencia de América Latina en cuarentena", Semanario Universidad, (Abril 2020), https://semanariouniversidad.com/mundo/violencia-domestica-la-otra-urgencia-deamerica-latina-en-cuarentena/

${ }^{31}$ Noticiero Telemetro, "Femicidios durante cuarentena por pandemia impactan en Panamá, Defensoría del Pueblo", Telemetro, (2020), https://www.telemetro.com/nacionales/2020/04/18/femicidios-durante-cuarentena-por-pandemiaimpactan-en-panama-defensoria-del-pueblo/2786133.html

32 Voz de América, "ONU advierte sobre incremento de la violencia doméstica en el contexto de la pandemia", Despacho 505, (abril 2020), https://www.despacho505.com/onu-advierte-sobre-incremento-de-la-violenciadomestica-en-el-contexto-de-la-pandemial
} 
doméstica; riesgo que se incrementa con factores como el estrés, la ansiedad y crisis económicas a raíz de los despidos laborales que dejó la pandemia.

Además, diferentes medios de comunicación a nivel latinoamericano mencionan entre sus principales noticias que, en países como Argentina y México, motores de la lucha feminista, los números de femicidios se pueden incrementar hasta un $8 \%$ más que en el año anterior, sin embargo, la magnitud real del fenómeno puede estar siendo subestimada 33343536

4.1.2 Poblaciones más vulnerables a la violencia doméstica por el contexto de cuarentena sanitaria

La situación de confinamiento ha generado un gran desafío humanitario en múltiples sentidos, como se ha explicado, no sólo la salud física se encuentra en peligro, sino también la salud mental y el riesgo de que ciertos grupos poblacionales sufran violencia doméstica ha aumentado exponencialmente. Entre los grupos más vulnerables se destaca a las mujeres adultas, quienes sufren de manifestaciones violentas por parte sus parejas íntimas-sentimentales, tales como abuso físico, psicológico, sexual, e incluso, el femicidio. Asimismo, es importante mencionar que la vulnerabilidad de las mujeres aumenta cuando están bajo condición de discapacidad, migración indocumentada o como víctimas de trata de personas. 373839

En la misma línea, los niños, niñas y adolescentes, corresponden con una parte de la población que es vulnerable ante trastornos psicosociales y violencia doméstica por el confinamiento, como víctimas directas de maltrato, explotación, aislamiento social y separación

\footnotetext{
${ }^{33}$ María Salazar, "Mujeres, repercusiones del confinamiento a raíz del coronavirus y violencia doméstica", DelfinoCr, (abril 2020), https://delfino.cr/2020/04/mujeres-repercusiones-del-confinamiento-a-raiz-del-coronavirusy-violencia-domestica

${ }^{34}$ Programa de las Naciones Unidas para el Desarrollo, "La otra pandemia: violencia en el hogar en tiempos de cuarentena", Organización de las Naciones Unidas, (abril 2020), https://www.pe.undp.org/content/peru/es/home/presscenter/articles/2020/la-otra-pandemia--violencia-en-el-hogaren-tiempos-de-cuarentena.html

${ }^{35}$ Antonnio Guterres, "Las mujeres en el centro de las iniciativas de recuperación del COVID-19", Organizaciónn de las Naciones Unidas, (2020), https://www.un.org/es/coronavirus/articles/mujeres-centro-recuperacion-contracovid19

${ }^{36}$ UNICEF", UNICEF CR, (2020), https://www.unicef.org/costarica/comunicados-prensa/aumento-de-violencia

${ }^{37}$ Paula Umaña, "Confinamiento por coronavirus sube el riesgo de violencia intrafamiliar", El Observador, (2020), https://observador.cr/noticia/condiciones-de-confinamiento-por-covid-19-aumentarian-el-riesgo-de-violenciaintrafamiliar/

38 Organización de las Naciones Unidas, “El coronavirus golpea tres veces a las mujeres: por la salud, por la violencia doméstica y por cuidar de los otros", Organización de las Naciones Unidad, (Marzo 2020), https://news.un.org/es/story/2020/03/1471872

${ }^{39}$ María Inés Nugent,_"En tiempos de Covid-19 la violencia de género no entra en cuarentena”, La Izquierda Diario, (2020), http://www.laizquierdadiario.com/En-tiempos-de-Covid-19-la-violencia-de-genero-no-entra-en-cuarentena
} 
forzada de sus cuidadores; o como víctimas indirectas, al ser espectadores de formas de violencia intrafamiliar. Particularmente, las mujeres menores de edad, suelen sufrir mayor riesgo de maltrato o abuso sexual por parte de familiares y la amenaza de matrimonio infantil. ${ }^{40} 4142$

Otro aspecto importante es que las personas adultas mayores pueden ser uno de los grupos más afectados por el aislamiento domiciliar, debido a que el alto riesgo de contagio les obliga a permanecer en el hogar con mayores restricciones de socialización, por lo que se encuentran más expuestas a la convivencia con persona agresora en su hogar y, por tanto, a situaciones de maltrato intrafamiliar y de exclusión social agravada. ${ }^{43} 44$

4.1.3 Factores psicosociales relacionados con la violencia doméstica manifestada en contexto de cuarentena sanitaria

Muchas de las noticias y notas de prensa que se analizaron coincidían en que existen diversos factores psicosociales que inciden en el desencadenamiento de la violencia doméstica, tales como: las presiones socioeconómicas y sentimientos de frustración e impotencia por el desempleo; las emociones ligadas al miedo, pánico e incertidumbre por enfermar de COVID-19; las manifestaciones de ansiedad y angustia por vivir en lugares reducidos sin espacios al aire libre; una alteración generalizada en la toma de decisiones y un mayor consumo de sustancias, en especial de bebidas alcohólicas. Cabe señalar que todos estos cambios experimentados a raíz del contexto de pandemia, han generado una desestabilización en la rutina diaria de las personas y sus familias, de sus amistades y las comunidades en general, dando paso a consecuencias negativas en su

\footnotetext{
${ }^{40}$ Paula Umaña, "Confinamiento por coronavirus sube el riesgo de violencia intrafamiliar", El Observador, (2020), https://observador.cr/noticia/condiciones-de-confinamiento-por-covid-19-aumentarian-el-riesgo-de-violenciaintrafamiliar/

${ }^{41}$ Organización de las Naciones Unidas, “El coronavirus golpea tres veces a las mujeres: por la salud, por la violencia doméstica y por cuidar de los otros", Organización de las Naciones Unidad, (Marzo 2020), https://news.un.org/es/story/2020/03/1471872

${ }^{42}$ María Inés Nugent,_"En tiempos de Covid-19 la violencia de género no entra en cuarentena”, La Izquierda Diario, (2020), http://www.laizquierdadiario.com/En-tiempos-de-Covid-19-la-violencia-de-genero-no-entra-en-cuarentena

${ }^{43}$ Paula Umaña, "Confinamiento por coronavirus sube el riesgo de violencia intrafamiliar", El Observador, (Marzo 2020), https://observador.cr/noticia/condiciones-de-confinamiento-por-covid-19-aumentarian-el-riesgo-de-violenciaintrafamiliar/

${ }^{44}$ Noticiero Telemetro, "Femicidios durante cuarentena por pandemia impactan en Panamá, Defensoría del Pueblo", Telemetro, (Abril 2020), https://www.telemetro.com/nacionales/2020/04/18/femicidios-durante-cuarentena-porpandemia-impactan-en-panama-defensoria-del-pueblo/2786133.html
} 
bienestar, así como en el desarrollo saludable y la adecuada protección de la niñez y la adolescencia. ${ }^{45} 464748$

Otro factor psicosocial destacado por las noticias/notas de prensa analizadas, es la relación entre la violencia doméstica ejercida y el sistema patriarcal en el contexto de confinamiento. Se plantea que las restricciones de circulación, así como la dependencia financiera de muchas mujeres hacia sus parejas, ha acentuado los mecanismos de poder y control sobre ellas. No obstante, la información en estudio da cuenta de que el cierre de bares y la suspensión del fútbol puede ser un indicador de disminución en los casos de violencia en dichos escenarios. dichos escenarios; asimismo, destaca la concientización. 495051

El contenido de las noticias y notas de prensa en cuestión también enfatiza que las medidas sanitarias adoptadas por los diferentes países para la prevención del contagio, entre ellas el confinamiento domiciliar y las disposiciones sobre el teletrabajo, han sido factores psicosociales que promueven, a su vez, un contacto permanente de la víctima con la persona que ejerce violencia doméstica. Un elemento clave que se resalta, es el hogar como el principal escenario de violencia hacia la mujer previo al contexto de cuarentena y durante la misma. Por tanto, se plantea reiteradamente que si bien la cuarentena previene que muchas mujeres enfermen por COVID-19,

\footnotetext{
${ }^{45}$ Semanario Universidad, "Violencia doméstica, la otra urgencia de América Latina en cuarentena", Semanario Universidad, (2020), https://semanariouniversidad.com/mundo/violencia-domestica-la-otra-urgencia-de-americalatina-en-cuarentena/_

${ }^{46}$ María Salazar, "Mujeres, repercusiones del confinamiento a raíz del coronavirus y violencia doméstica", DelfinoCr, (Abril 2020), https://delfino.cr/2020/04/mujeres-repercusiones-del-confinamiento-a-raiz-del-coronavirus-y-violenciadomestica

${ }^{47}$ Paula Umaña, "Confinamiento por coronavirus sube el riesgo de violencia intrafamiliar", El Observador, (Marzo 2020), https://observador.cr/noticia/condiciones-de-confinamiento-por-covid-19-aumentarian-el-riesgo-de-violenciaintrafamiliar/

${ }^{48}$ Noticiero Everardo Herrera, "OMS enfatiza en que la venta de licor debe restringirse en medio de la pandemia", Noticiero Everardo Herrera, (2020), https://everardoherrera.com/index.php/fuera-de-juego-costa-rica/70-fuera-dejuego/63264-oms-enfatiza-en-que-la-venta-de-licor-debe-restringirse-en-medio-de-la-pandemia

${ }^{49}$ María Salazar, "Mujeres, repercusiones del confinamiento a raíz del coronavirus y violencia doméstica", DelfinoCr, (Abril 2020), https://delfino.cr/2020/04/mujeres-repercusiones-del-confinamiento-a-raiz-del-coronavirusy-violencia-domestica

${ }^{50}$ Organización de las Naciones Unidas-Mujeres. 2020. COVID-19 en América Latina y el Caribe: Cómo incorporar a las mujeres y la igualdad de género en la gestión de la respuesta a la crisis.

https://reliefweb.int/sites/reliefweb.int/files/resources/75751.pdf

${ }^{51}$ Departamento de Comunicación Global de las Naciones Unidas, "Igualdad de género en tiempos del COVID-19”, Organizaciónn de las Naciones Unidas, (2020), https://www.un.org/es/coronavirus/articles/igualdad-genero-covid$\underline{19}$
} 
su salud sigue siendo amenazada por la violencia de género a la que están expuestas en su seno familiar. 5253

Aunado a esto, en los países donde la cuarentena se declaró obligatoria, se alerta sobre el posible agravio en manifestaciones de violencia doméstica. Por ello, la Organización Mundial de la Salud ha declarado que hoy día, la sociedad se enfrenta a la violencia doméstica como otra pandemia silenciosa, que permanece en las sombras, haciendo metáfora a la privacidad y reserva que encierra el hogar.

Por otro lado, las notas de prensa y noticas señalan que durante este periodo de pandemia se ha visto un freno en las protestas públicas de muchas mujeres, por ejemplo, en Argentina, donde el movimiento «ni una menos» ha permanecido en pausa. En relación con esto, se evidencia que movimientos como «quédate en casa», que impulsan a la población a respetar la cuarentena en sus hogares no toma en cuenta problemáticas sociales como la violencia doméstica o pobreza. ${ }^{54} 55$

En la misma línea, el primer periodo de confinamiento ha demostrado las limitación que tienen un gran número de personas víctimas de violencia doméstica para acceder a diferentes servicios de apoyo comunitario, esto debido a la falta de recursos gubernamentales como, por ejemplo, la reducción en el acceso a refugios para víctimas de violencia y el amparo policiaco o judicial, ya que muchos tribunales se encuentran cerrados y los trámites para la solicitud de refugio deben realizarse a través de medios electrónicos, solo en el caso de contar con dicha modalidad. Asimismo, muchas mujeres han sufrido una reducción drástica al acceso de anticonceptivos, lo cual podría estar relacionado a un aumento de embarazos no deseados. ${ }^{56}$

\footnotetext{
52 Voz de América, "ONU advierte sobre incremento de la violencia doméstica en el contexto de la pandemia", Despacho 505, (2020), https://www.despacho505.com/onu-advierte-sobre-incremento-de-la-violencia-domestica-enel-contexto-de-la-pandemia/

${ }^{53}$ Allan Arroyo, “¿Aumentaron los casos de violencia doméstica con el aislamiento social?”, Columbia, (Marzo 2020), https://www.columbia.co.cr/noticias/coronavirus-covid-19/15324-aumentaron-los-casos-de-violencia-domestica-conel-aislamiento-social

${ }^{54}$ Ailyn Torres, "La seguridad de las mujeres frente al Covid-19: Nudos críticos para América Latina". Fundación Friedrich Ebert, http://library.fes.de/pdf-files/bueros/la-seguridad/16137.pdf

${ }^{55}$ Instituto Nacional de las Mujeres, "INAMU y Naciones Unidas reúnen esfuerzos para apoyar a mujeres en riesgo de violencia", Instituto Nacional de las Mujeres, (Mayo 2020), https://www.inamu.go.cr/web/inamu/inamu-ynaciones-unidas-reunen-esfuerzos-para-apoyar-a-mujeres-en-riesgo-de-violencia

${ }^{56}$ Noticiero El Mundo, "Millones de mujeres sufrirán embarazos no deseados durante la pandemia de coronavirus", Noticiero El mundo, (2020), https://www.elmundo.cr/mundo/millones-de-mujeres-sufriran-embarazos-no-deseadosdurante-la-pandemia-de-coronavirus/
} 
4.1.4 Mecanismos de denuncia y apoyo a las personas víctimas de violencia doméstica en contexto de confinamiento

Como se ha comentado anteriormente, la situación de la pandemia puede ser el detonante de un incremento en diversas formas de violencia de género y violencia doméstica. Para prevenir este posible incremento, diversas organizaciones de ayuda a la mujer han implementado múltiples canales de atención para realizar denuncias, por ejemplo, la mensajería instantánea y el uso de palabras claves o códigos en lugares como supermercados o farmacias, con el fin de abordar la situación de manera en que la persona agresora no perciba la denuncia y así evitar posibles amenazas o mayores riesgos para la vida de la persona denunciante. 575859

Sin embargo, los primeros informes sobre estas herramientas muestran que no han sido suficientes para lograr que la víctima se comunique con los centros de ayuda sin alertar a la persona agresora. Junto a esto, se presenta el fenómeno de que, en países como Francia y Argentina, el número de llamadas de emergencia por violencia doméstica ha disminuido. Se sospecha que esta disminución está relacionada con el constante monitoreo que puede presentarse por parte de la persona agresora ${ }^{60}$.

La literatura relacionada a la violencia doméstica y de género plantea que los Estados deben garantizar acceso a la protección, refugios seguros y líneas de ayuda para las víctimas, proveyendo de medios que se adecuen cada vez más a la situación del confinamiento y la convivencia con la persona agresora. Asimismo, enfatizan en la importancia de que los miembros de la policía o seguridad pública cuenten con la debida sensibilización en el tema de violencia doméstica y de género, con el fin de que su actuar sea rápido y se puedan prevenir desenlaces fatales.

De igual forma, las noticias y notas de prensa que fueron recopiladas para esta investigación resaltan que los esfuerzos interinstitucionales realizados para dar apoyo a las víctimas de violencia en el contexto de la pandemia deben permitir que las poblaciones vulnerables tengan acceso a

${ }^{57}$ María Salazar, "Mujeres, repercusiones del confinamiento a raíz del coronavirus y violencia doméstica", DelfinoCr, (2020) https://delfino.cr/2020/04/mujeres-repercusiones-del-confinamiento-a-raiz-del-coronavirus-yviolencia-domestica

${ }^{58}$ Paula Umaña, "Confinamiento por coronavirus sube el riesgo de violencia intrafamiliar", El Observador, (2020), https://observador.cr/noticia/condiciones-de-confinamiento-por-covid-19-aumentarian-el-riesgo-de-violenciaintrafamiliar/

${ }^{59}$ Voz de América, "ONU advierte sobre incremento de la violencia doméstica en el contexto de la pandemia", Despacho 505, (2020), https://www.despacho505.com/onu-advierte-sobre-incremento-de-la-violencia-domestica-enel-contexto-de-la-pandemia/

${ }^{60}$ María Inés Nugent, "En tiempos de Covid-19 la violencia de género no entra en cuarentena", La Izquierda Diario, (2020), http://www.laizquierdadiario.com/En-tiempos-de-Covid-19-la-violencia-de-genero-no-entra-en-cuarentena 
acompañamiento psicológico, asesoría legal y al servicio de Trabajo Social, esto a través de vías telefónicas y correos electrónicos; conjuntamente, dichos servicios deben brindarse de manera gratuita. Además, se destacan ayudas sociales, como canastas de víveres con mensajes de sensibilización sobre la importancia de las responsabilidades compartidas en el hogar y masculinidades y paternidades sanas, con el fin de prevenir la violencia doméstica. ${ }^{61} 62$

\section{Análisis desde un enfoque de género: mensajes sociales encontrados en la prensa escrita}

A lo largo de este artículo se ha evidenciado que existe una problemática social y de salud pública relacionada a la violencia doméstica, la cual, principalmente, afecta a mujeres. Las diferentes notas de prensa y noticas revisadas en esta investigación plantean que la crisis que ha surgido a raíz del confinamiento por el virus no ha llegado más que a agudizar un desafío humanitario que existía desde hace mucho tiempo con respecto a este tema.

Sobre esto, investigadoras como Gerda Lerner ${ }^{63}$ plantean que la subordinación femenina proviene desde la primitiva división sexual del trabajo, con la abolición del derecho a la libertad maternal, y con ello, una posterior sujeción al dominio del hombre sobre su cuerpo, sus decisiones y su rol social, lo cual evidencia que la creencia de la supremacía masculina continúa expresándose en manifestaciones de violencia de género, ampliamente ejercida en Latinoamérica ${ }^{64}$

En la misma línea, la investigadora Sandra Pereira ${ }^{65}$ menciona que la violencia doméstica, además de ser ejercida en el contexto familiar, también se presenta en relaciones afectivas y de confianza, como se evidencia en las noticas y notas de prensa analizadas, lo cual resalta que las

\footnotetext{
${ }^{61}$ Alianza para la protección de la niñez y adolescencia en la acción humanitaria, "Protección de la niñez y adolescencia durante la pandemia del coronavirus", (2020), https://www.unicef.org/costarica/media/2191/file/Nota\%20t\%C3\%A9cnica:\%20Protecci\%C3\%B3n\%20de\%20la\%2 0ni\%C3\%B1ez\%20y\%20adolescencia\%20durante\%201a\%20pandemia\%20del\%20coronavirus\%20.pdf

${ }^{62}$ Departamento de Comunicación Global de las Naciones Unidas, "Igualdad de género en tiempos del COVID-19", Organización de las Naciones Unidas, (abril 2020), https://www.un.org/es/coronavirus/articles/igualdad-generocovid-19

${ }^{63}$ Gerda Lerne, La creación del patriarcado, Katakrak Liburuak (2017).

${ }^{64}$ Programa de las Naciones Unidas para el Desarrollo, "La otra pandemia: violencia en el hogar en tiempos de cuarentena", Organización de las Naciones Unidas, (Abril 2020), https://www.pe.undp.org/content/peru/es/home/presscenter/articles/2020/la-otra-pandemia--violencia-en-el-hogaren-tiempos-de-cuarentena.html

${ }^{65}$ Sandra Pereira. Violencia contra las mujeres en la relación de pareja: Diagnóstico realizado en el Juzgado Contra la Violencia Doméstica de Cartago para un Abordaje integral en el Poder Judicial de la Violencia Intrafamiliar desde la perspectiva de Género. (Tesis de Maestría Profesional en Violencia Intrafamiliar y de Género, Universidad de Costa Rica, 2018).
} 
poblaciones socialmente vulnerables suelen ser maltratadas por hombres inmersos en la estructura patriarcal. Esto también se denota en los informes estadísticos sobre el estado de la violencia en Latinoamérica, ${ }^{66} 67$ lo cual afirma que la violencia de género suele estar directamente enfocada hacia la mujer. Por ello, los movimientos feministas, las organizaciones de mujeres, las instituciones públicas y los organismos internacionales coinciden en reconocer que este tipo de violencia está presente a lo largo de todo el ciclo vital de las mujeres, atraviesa todas las culturas, razas, etnias, clases y religiones, y tiene fuertes efectos de malestar psicológico en las mujeres que la sufren. ${ }^{68}$

En la misma línea, en las diferentes noticias y notas de prensa analizadas se menciona que en las mujeres se incrementa el riesgo de vulnerabilidad por otras condiciones, entre ellas las discapacidades, el ser migrantes indocumentadas o víctimas de trata de personas. Ante esto, el concepto de violencias interseccionales permite entender que la opresión femenina en Latinoamérica se da en multiplicidad y simultaneidad de situaciones; además, se deben tomar en cuenta condiciones como el embarazo, la pobreza y marginación social, el racismo, la discriminación por la edad y el heterosexismo. ${ }^{69} 7071$

Adicionalmente, María Salazar ${ }^{72}$ propone que la violencia de género tiende a aumentar en situaciones de confinamiento, ya que cuando hay un estado de crisis la regulación emocional es menor y esto desemboca en violencia intrafamiliar y violencia de género. Sin embargo, se debe tomar en cuenta que la violencia hacia la mujer ya era una problemática social y sanitaria fuerte y

\footnotetext{
${ }^{66}$ Observatorio de violencia de género contra las mujeres y acceso a la justicia. "Femicidio", https://observatoriodegenero.poder-judicial.go.cr/soy-especialista-y-busco/estadisticas/femicidio/ (consultado el 22 marzo 2020).

${ }^{67}$ Organización de las Naciones Unidas-Mujeres, "Prevención de la violencia contra las mujeres frente a COVID-19 en América Latina y el Caribe", Organización de las Naciones Unidas,

https://lac.unwomen.org/es/digiteca/publicaciones/2020/04/prevencion-de-la-violencia-contra-las-mujeres-frente-acovid-19

${ }^{68}$ Mariángel Álvarez, Ana Sánchez y Pepa Bojó, Manual de atención psicológica a víctimas de maltrato machista. Colegio Oficial de Psicología de Gipuzkoa, (2016).

${ }^{69}$ Patricia Muñoz, Violencias interseccionales. Debates feministas y marcos teóricos en el tema de pobreza y violencia contra las mujeres en Latinoamérica. Editorial CAWN, (2001).

${ }^{70}$ Soledad Valle, La Interseccionalidad como herramienta metodológica para el análisis cualitativo de las vivencias de las mujeres víctimas de violencia de género: caleidoscopio de desigualdades y múltiples discriminaciones.

Investigación Cualitativa en Ciencias Sociales, 3, (2016): 203-207.

${ }^{71}$ Gabriela Arguedas, La violencia obstétrica: propuesta conceptual a partir de la experiencia costarricense. Cuadernos Inter.c.a.mbio sobre Centroamérica y el Caribe, 11(1), (2014):145-169.

${ }^{72}$ María Salazar, "Mujeres, repercusiones del confinamiento a raíz del coronavirus y violencia doméstica", DelfinoCr, (2020), https://delfino.cr/2020/04/mujeres-repercusiones-del-confinamiento-a-raiz-del-coronavirus-yviolencia-domestica
} 
presente a lo largo de toda Latinoamérica y el mundo, causante de lesiones físicas, enfermedades, trastornos psicológicos y emocionales. En suma, presenta una fuerte presencia de factores psicosociales, y con esto, el surgimiento de la necesidad de que instituciones de ayuda brinden apoyo a las personas víctimas de violencia doméstica y que quienes que trabajan en ellas estén preparadas para identificar y abordar de manera integral la situación. ${ }^{73}$

En ese sentido, Salazar ${ }^{74}$ describe que las mujeres víctimas de violencia doméstica siempre están en emergencia y ahora con la pandemia sus vidas corren el doble de peligro, no sólo por el COVID-19 que es invisible, sino también por el virus más letal: el patriarcado, que ha estado en la sociedad por mucho tiempo. Por lo tanto, se debe entender que la violencia hacia la mujer es un problema social de elevada magnitud y pautado en la desigualdad de género, un problema público, una negación de los derechos de ciudadanía y un hecho de justicia ${ }^{75}$; lo cual es otro de los mensajes presentes en el material de prensa analizado.

Aunado a lo anterior, se evidencia el llamado de atención que hace la prensa escrita sobre la posible la amenaza hacia mujeres y niñas, pues esta se cierne precisamente en el lugar donde deberían estar más seguras: en sus propios hogares. ${ }^{76}$ De la misma manera, se puede argumentar que las mujeres se encuentran frente a una sociedad desvertebrada, donde se enfrentan solas con la lucha por la supervivencia de sus hijos, hijas y ellas mismas. Por lo tanto, queda clara la necesidad de que cada vez existan más medios por los cuales las mujeres se puedan resguardar y, más aún, que puedan alejarse de situaciones de riesgo ${ }^{77}$.

Sobre esto es válido recordar el concepto de Ruta Crítica, la cual puede ser entendida como el proceso por el cual una mujer toma la decisión y determinación de apropiarse de su vida y las de sus hijos. Durante la pandemia que vive el mundo por el COVID-19, se encuentran noticias

\footnotetext{
${ }^{73}$ Sandra Pereira. Violencia contra las mujeres en la relación de pareja: Diagnóstico realizado en el Juzgado Contra la Violencia Doméstica de Cartago para un Abordaje integral en el Poder Judicial de la Violencia Intrafamiliar desde la perspectiva de Género. (Tesis de Maestría Profesional en Violencia Intrafamiliar y de Género, Universidad de Costa Rica, 2018).

${ }^{74}$ María Salazar, "Mujeres, repercusiones del confinamiento a raíz del coronavirus y violencia doméstica", DelfinoCr, (2020), https://delfino.cr/2020/04/mujeres-repercusiones-del-confinamiento-a-raiz-del-coronavirus-yviolencia-domestica

${ }^{75}$ Montserrat Sagot, La ruta crítica de las mujeres afectadas por la violencia intrafamiliar en América Latina (Estudios de Casos en 10 países), Zeta Servicios Gráficos, (2000).

${ }^{76}$ Organización de las Naciones Unidas, "El coronavirus golpea tres veces a las mujeres: por la salud, por la violencia doméstica y por cuidar de los otros", Organización de las Naciones Unidad, (2020), https://news.un.org/es/story/2020/03/1471872

${ }^{77}$ Nuria Varela, Feminismo para principiantes, Ediciones B, (2008).
} 
de diversos países de Latinoamérica que exponen la preocupación de que muchas mujeres estén en sus casas, encerradas con las personas que les hacen daño y que, por este motivo, la determinación que brindaron los factores que las impulsaron a buscar ayuda, se topan con elementos inhibidores, tales como la culpa y el miedo, dificultades que, en muchos casos, detienen el proceso. ${ }^{78} 7980$

Junto con lo anterior, se descubrió que la voz de protesta por violencia doméstica ha disminuido, pero no porque la violencia haya cesado, ni porque las mujeres dejaran de luchar por sus vidas y las de sus hijos e hijas, sino por la incapacidad de poder acceder a servicios fundamentales, como lo son la libertad de tránsito y el derecho para vivir una vida libre de violencia. Entre lo que se expone en las noticias de la región Latinoamericana se encuentran frases como: "El actual aislamiento obligatorio por la pandemia de COVID-19, eliminó nuestro grito de las calles" ${ }^{\prime \prime}$; donde se entiende que la fuerte lucha feminista que se venía dando en los espacios públicos se ha visto frenada por la pandemia.

Finalmente, el recorrido por los discursos en las noticias y notas de prensa analizadas permite evidenciar la brecha que existe la brecha que existe entre la condición social masculina, heteronormativa y hegemónica, y las poblaciones socialmente vulnerables. Además, se evidencia la necesidad de generar nuevas formas de comunicación y organización que atiendan los casos de violencia y que, consecuentemente, permitan la protección, el acompañamiento y la colaboración de redes de apoyo. Sumado a esto, existe una gran necesidad de que los Estados generen nuevos mecanismos de denuncia, los cuales sean más accesibles y contextualizados en las diversas situaciones que viven las víctimas, y que a su vez, sean ejecutados de manera integral.

\footnotetext{
${ }^{78}$ María Salazar, "Mujeres, repercusiones del confinamiento a raíz del coronavirus y violencia doméstica", DelfinoCr, (2020), https://delfino.cr/2020/04/mujeres-repercusiones-del-confinamiento-a-raiz-del-coronavirus-yviolencia-domestica

${ }^{79}$ Paula Umaña, "Confinamiento por coronavirus sube el riesgo de violencia intrafamiliar", El Observador, (2020), https://observador.cr/noticia/condiciones-de-confinamiento-por-covid-19-aumentarian-el-riesgo-de-violenciaintrafamiliar/

${ }^{80}$ Montserrat Sagot, La ruta crítica de las mujeres afectadas por la violencia intrafamiliar en América Latina (Estudios de Casos en 10 países), Zeta Servicios Gráficos, (2000).

${ }^{81}$ María Inés Nugent, "En tiempos de Covid-19 la violencia de género no entra en cuarentena”, La Izquierda Diario, (Abril 2020), http://www.laizquierdadiario.com/En-tiempos-de-Covid-19-la-violencia-de-genero-no-entra-encuarentena
} 


\section{๑rume}

Wimblu, Rev. Estud. de Psicología UCR, 16(2) 2021 (Julio-Diciembre): 35-65 /ISSN: 1659-2107

\section{Conclusiones}

La violencia doméstica representa una problemática social que ha permanecido a lo largo del tiempo, cuyo impacto en la salud pública significa un desafío que atenta en diferentes aspectos, por ejemplo, el área física, psicológica, socioeconómica, e incluso, la vida misma.

Este artículo investigativo busca realizar un análisis exploratorio de contenido de prensa escrita latinoamericana publicada en el período marzo a mayo del año 2020, en el cual se encontró la posibilidad de que en los núcleos familiares aumente el riesgo de sufrir violencia doméstica, de la mano con un posible incremento de casos de femicidio relacionado a las medidas de confinamiento impuestas en los diferentes países para evitar la propagación del virus.

Asimismo, a lo largo de este análisis se evidenció que las principales víctimas de violencia doméstica suelen ser mujeres, tanto adultas como niñas; seguido de menores de edad y personas adultas mayores, debido a la permanencia en el hogar con las personas agresoras. Además, en la prensa escrita revisada, se señalan factores psicosociales que pueden influir en el desencadenamiento de la violencia, tales como el estrés por el desempleo, el confinamiento, el aumento de consumo de bebidas alcohólicas y, con esto, una desestabilización generalizada que conduce a consecuencias negativas en el bienestar y la salud.

De la mano con lo anterior, el análisis desde el enfoque de género permite concluir que la violencia doméstica se presenta como una problemática de la cual ya se conocía su gravedad, pero que el contexto de confinamiento podría propiciar a la persona agresora mecanismos de control y poder más fuertes de los que tenía anteriormente. En el mismo orden, el contexto de cuarentena sanitaria ha evidenciado las consecuencias de un sistema patriarcal aún arraigado en las sociedades actuales, así como que la violencia doméstica continúa afectando la calidad de vida de muchas personas, principalmente mujeres.

Si bien las luchas sociales en contra de la violencia de género han presentado una pausa durante este primer periodo de la crisis sanitaria, la violencia doméstica que se presenta no pasa desapercibida por la prensa escrita, proponiendo a los Estados que las agendas políticas deben enfocar la atención en los diversos casos de violencia doméstica y de género, así como velar por el cumplimiento de los derechos humanos de todas las personas.

En futuras investigaciones relacionadas a la violencia doméstica y la situación del COVID19 se recomienda profundizar en discursos de medios televisivos, notas de prensa y noticas de 
periódicos locales o autónomos, esto con el fin de ampliar la muestra investigativa y comprender mejor el fenómeno desde los diversos puntos de vista que pueden ser plasmarse en los medios.

\section{Referencias bibliográficas}

Alianza para la protección de la niñez y adolescencia en la acción humanitaria, Protección de la niñez y adolescencia durante la pandemia del coronavirus, (2020b). https://www.unicef.org/costarica/media/2191/file/Nota\%20t\%C3\%A9cnica:\%20Protecci\%C3 \%B3n\%20de\%201a\%20ni\%C3\%B1ez\%20y\%20adolescencia\%20durante\%20la\%20pandemia $\% 20 \mathrm{de} 1 \% 20$ coronavirus\%20.pdf

Álvarez, Mariángel, Sánchez, Ana y Bojó, Pepa, Manual de atención psicológica a víctimas de maltrato machista. Colegio Oficial de Psicología de Gipuzkoa, (2016).

Arguedas, Gabriela, La violencia obstétrica: propuesta conceptual a partir de la experiencia costarricense, Cuadernos Intercambio sobre Centroamérica y el Caribe, 11(1), 2014:145-169.

Asociación Venezolana para una Educación Sexual Alternativa (AVESA), Mujeres al Límite, el peso de la emergencia humanitaria: vulneración de los derechos humanos de las mujeres en Venezuela, 2017 , https://clacaidigital.info/bitstream/handle/123456789/1109/Mujeres\%20al\%20limite.pdf?sequ ence $=5 \&$ is Allowed $=\mathrm{y}$

Bazaco, Ángela, Redondo, Marta, Sánchez-García, Pilar, El clickbait como estrategia del periodismo viral: concepto y metodología. Revista Latina de Comunicación Social, 74, 2019: 94-115, http://www.revistalatinacs.org/074paper/1323/RLCS-paper1323.pdf

Biasutto, Miguel Ángel, Noticia y mensaje: lectura e interpretación en los medios. COMUNICAR, 4 , (1995): 29-36, https://www.revistacomunicar.com/ojs/index.php/comunicar/article/view/C04-1995-06

Bradbury-Jones, Caroline y Isham, Louise, The pandemic paradox: The consequences of COVID19 on domestic violence. Journal of Clinical Nursing, 29, (2020): 20472049, https://onlinelibrary.wiley.com/doi/epdf/10.1111/jocn.15296

Buvinić, Mayra, Morrison, Andrew y Shifter, Michael, La Violencia en América Latina y el Caribe: Un Marco de Referencia para la Acción. Banco Interamericano de Desarrollo, (1999), 
مिumaw

Wimblu, Rev. Estud. de Psicología UCR, 16(2) 2021 (Julio-Diciembre): 35-65 /ISSN: 1659-2107

https://www.cepal.org/mujer/noticias/paginas/3/27453/BID.los\%20costos\%20de\%20la\%20vio lencia.pdf

Campbell, Andrew, An increasing risk of family violence during the Covid-19 pandemic: Strengthening community collaborations to save lives. Forensic Science International: Reports, 2, (2020): 1-3, https://www.ncbi.nlm.nih.gov/pmc/articles/PMC7152912/

Claramunt, María Cecilia, Casitas quebradas: El problema de la violencia doméstica en Costa Rica. Editorial Universidad Estatal a Distancia, (2006).

Davies, Sara, and Belinda Bennett. "A Gendered Human Rights Analysis Of Ebola And Zika: Locating Gender In Global Health Emergencies". International Affairs, , (2016). https://doi.org/10.1111/1468-2346.12704.Observatorio de violencia de género contra la mujeres y acceso a la justicia (2020a). Femicidio. https://observatoriodegenero.poder-judicial.go.cr/soyespecialista-y-busco/estadisticas/femicidio/

Harman, Sophie, Ebola, gender and conspicuously invisible women in global health governance, Third World Quarterly, 37(3), (2016): 524-541.

Lerner, Gerda, La creación del patriarcado. Katakrak Liburuak, (2017).

Muñoz, Patricia, Violencias interseccionales. Debates feministas y marcos teóricos en el tema de pobreza y violencia contra las mujeres en Latinoamérica. Editorial CAWN, (2001).

Observatorio de violencia de género contra la mujeres y acceso a la justicia, Femicidio, 2020a, https://observatoriodegenero.poder-judicial.go.cr/soy-especialista-ybusco/estadisticas/femicidio/

Observatorio de violencia de género contra la mujeres y acceso a la justicia, Violencia doméstica, (2020b), https://observatoriodegenero.poder-judicial.go.cr/soy-especialista-ybusco/estadisticas/violencia-domestica/

Organización de las Naciones Unidas-Mujeres. Informe Anual 2018-2019, (2019), https://www.unwomen.org/-/media/annual\%20report/attachments/sections/library/2019/unwomen-annual-report-2018-2019-es.pdf?la=es\&vs=5038

Organización de las Naciones Unidas-Mujeres. COVID-19 en América Latina y el Caribe: Cómo incorporar a las mujeres y la igualdad de género en la gestión de la respuesta a la crisis, (2020), https://reliefweb.int/sites/reliefweb.int/files/resources/75751.pdf

Pereira, Sandra, Salud, mujeres y violencia doméstica. Revista Judicial del Poder Judicial de Costa Rica, 123, (2018): 25-39. 
Programa de las Naciones Unidas para el Desarrollo, Comparación de las políticas sobre violencia doméstica en América Latina: penalización, empoderamiento de víctimas y rehabilitación de agresores, (2017), https://www.undp.org/content/dam/el_salvador/docs/womempow/CuadernoGenero3_SP.pdf

República de Costa Rica, Ley No.7586 Contra la Violencia Doméstica, (1996).

Rey, German, Martini, Stella, Marroquín, Amparo, Altamirano, Xavier, Roncallo, Sergio, Wondratschke, Claudia y Betancourt, Alberto, Los relatos periodísticos del crimen. Centro de Competencia en Comunicación para América Latina, (2017), https://library.fes.de/pdffiles/bueros/c3-comunicacion/07327.pdf

Rodríguez, Adriana, El tiempo de las mujeres: trabajo y malestar femenino en tiempos de pandemia. Reflexiones, 99(2), (2020):1-10.

Sagot, Montserrat, La ruta crítica de las mujeres afectadas por la violencia intrafamiliar en América Latina (Estudios de Casos en 10 países), Zeta Servicios Gráficos, (2000).

Torres, Ailyin, La seguridad de las mujeres frente al Covid-19: Nudos críticos para América Latina, Fundación Friedrich Ebert, (2020) http://library.fes.de/pdf-files/bueros/laseguridad/16137.pdf

Unidad de Salud Mental y Uso de Sustancias y la Organización Panamericana de la Salud Protección de la salud mental y atención psicosocial en situaciones de epidemias, (2016), https://www.paho.org/disasters/index.php?option=com_docman\&view=download\&category_s $\underline{\text { lug=informes-tecnicos\&alias=2539-proteccion-salud-mental-atencion-psicosocial-situaciones- }}$ epidemias-2016-539\&Itemid=1179\&lang=en

United Nation Secretary-General's Campaign. s.f. UNIFEM Haití: Apoyar la capacidad nacional en la violencia de género es una tarea impostergable. https://www.cepal.org/mujer/noticias/noticias/5/41145/UNIFEM_Haiti_Apoyar.pdf

Usher, Kim, Bhullar, Navjot, Durkin, Joanne, Gyamfi, Naomi y Jackson, Debre, Family violence and COVID-19: Increased vulnerability and reduced options for support. International Journal of Mental Health Nursing, 29, (2020): 549-552. https://onlinelibrary.wiley.com/doi/epdf/10.1111/inm.12735

Valle, Soledad. 2016. La Interseccionalidad como herramienta metodológica para el análisis cualitativo de las vivencias de las mujeres víctimas de violencia de género: caleidoscopio de 
Wimblu, Rev. Estud. de Psicología UCR, 16(2) 2021 (Julio-Diciembre): 35-65 /ISSN: 1659-2107

desigualdades y múltiples discriminaciones. Investigación Cualitativa en Ciencias Sociales, 3 , 203-207.

Varela, Nuria. 2008. Feminismo para principiantes. Ediciones B.

\section{Noticias y notas de prensa escrita utilizadas como unidades de análisis}

Alianza para la protección de la niñez y adolescencia en la acción humanitaria, Nota técnica: "Protección de la niñez y adolescencia durante la pandemia del coronavirus", UNICEF, (Marzo 2020), https://www.unicef.org/costarica/informes/nota-tecnica-alianza

Arroyo, Allan, “¿Aumentaron los casos de violencia doméstica con el aislamiento social?”, Columbia, (2020), https://www.columbia.co.cr/noticias/coronavirus-covid-19/15324aumentaron-los-casos-de-violencia-domestica-con-el-aislamiento-social

Arias, Andrei, "COVID-19: Ante el endurecimiento de las medidas de contención, aumenta el riesgo de que los niños sufran abusos, abandono, explotación y violencia, dice UNICEF”, UNICEF CR, (2020), https://www.unicef.org/costarica/comunicados-prensa/aumento-deviolencia

Guterres, Antonnio, "Las mujeres en el centro de las iniciativas de recuperación del COVID-19", Organizaciónn de las Naciones Unidas, (2020), https://www.un.org/es/coronavirus/articles/mujeres-centro-recuperacion-contra-covid19

Tórrez, Cinthya, “¿Cuál es la otra pandemia que el Covid-19 ha dejado en las sombras?” , La Prensa, (2020), https://www.laprensa.com.ni/2020/04/16/nacionales/2663704-cual-es-la-otrapandemia-que-el-covid-19-ha-dejado-en-las-sombras

Departamento de Comunicación Global de las Naciones Unidas, "Igualdad de género en tiempos del COVID-19", Organizaciónn de las Naciones Unidas, (2020), https://www.un.org/es/coronavirus/articles/igualdad-genero-covid-19

Correa, Hugo, "Van al menos 180 detenidos por violencia doméstica durante confinamiento social en Argentina", Noticiero CÑ̃̃, (2020), https://cnnespanol.cnn.com/video/violencia-de-generopandemia-cuarentena-machismo-pkg-hugo-manu-correa-perspectivas-buenos-aires/

Instituto Nacional de las Mujeres, "INAMU y Naciones Unidas reúnen esfuerzos para apoyar a mujeres en riesgo de violencia”, Instituto Nacional de las Mujeres, (2020), https://www.inamu.go.cr/web/inamu/inamu-y-naciones-unidas-reunen-esfuerzos-para-apoyara-mujeres-en-riesgo-de-violencia 
Nugent, María Inés, "En tiempos de Covid-19 la violencia de género no entra en cuarentena”, La Izquierda Diario, (2020), http://www.laizquierdadiario.com/En-tiempos-de-Covid-19-laviolencia-de-genero-no-entra-en-cuarentena

Salazar, María, "Mujeres, repercusiones del confinamiento a raíz del coronavirus y violencia doméstica", DelfinoCr, (2020), https://delfino.cr/2020/04/mujeres-repercusiones-delconfinamiento-a-raiz-del-coronavirus-y-violencia-domestica

Noticiero El Mundo, "Millones de mujeres sufrirán embarazos no deseados durante la pandemia de coronavirus", Noticiero El mundo, (2020), https://www.elmundo.cr/mundo/millones-demujeres-sufriran-embarazos-no-deseados-durante-la-pandemia-de-coronavirus/

Noticiero Everardo Herrera, "OMS enfatiza en que la venta de licor debe restringirse en medio de la pandemia", Noticiero Everardo Herrera, (2020), https://everardoherrera.com/index.php/fuera-de-juego-costa-rica/70-fuera-de-juego/63264oms-enfatiza-en-que-la-venta-de-licor-debe-restringirse-en-medio-de-la-pandemia

Noticiero Telemetro, "Femicidios durante cuarentena por pandemia impactan en Panamá, Defensoría del Pueblo", Telemetro, (2020), https://www.telemetro.com/nacionales/2020/04/18/femicidios-durante-cuarentena-porpandemia-impactan-en-panama-defensoria-del-pueblo/2786133.html

Organización de las Naciones Unidas, “El coronavirus golpea tres veces a la mujeres: por la salud, por la violencia doméstica y por cuidar de los otros", Organización de las Naciones Unidad, (2020), https://news.un.org/es/story/2020/03/1471872

Organización de las Naciones Unidas-Mujeres, "Prevención de la violencia contra las mujeres frente a COVID-19 en América Latina y el Caribe", Organización de las Naciones Unidas, (2020), $\quad$ https://lac.unwomen.org/es/digiteca/publicaciones/2020/04/prevencion-de-laviolencia-contra-las-mujeres-frente-a-covid-19

Umaña, Paula, "Confinamiento por coronavirus sube el riesgo de violencia intrafamiliar", El Observador, (2020), https://observador.cr/noticia/condiciones-de-confinamiento-por-covid-19aumentarian-el-riesgo-de-violencia-intrafamiliar/

Mlambo-Ngcuka, Phumzile, "Violencia contra las mujeres: la pandemia en la sombra", Organizaciónn de las Naciones Unidas, (2020), https://www.unwomen.org/es/news/stories/2020/4/statement-ed-phumzile-violence-againstwomen-during-pandemic 
Wimblu, Rev. Estud. de Psicología UCR, 16(2) 2021 (Julio-Diciembre): 35-65 /ISSN: 1659-2107

Programa de las Naciones Unidas para el Desarrollo, "La otra pandemia: violencia en el hogar en tiempos de cuarentena", Organización de las Naciones Unidas, (2020), https://www.pe.undp.org/content/peru/es/home/presscenter/articles/2020/la-otra-pandemia-violencia-en-el-hogar-en-tiempos-de-cuarentena.html

Semanario Universidad, "Violencia doméstica, la otra urgencia de América Latina en cuarentena", Semanario Universidad, (2020), https://semanariouniversidad.com/mundo/violenciadomestica-la-otra-urgencia-de-america-latina-en-cuarentena/

Navas, Valeria, "INAMU prevé aumento en violencia doméstica por estrés relacionado a COVID19”, Amelia Rueda, (2020), https://www.ameliarueda.com/nota/covid19-coronavirus-casosviolencia-domestica-costa-rica-aumento

Voz de América, "ONU advierte sobre incremento de la violencia doméstica en el contexto de la pandemia", Despacho 505, (2020), https://www.despacho505.com/onu-advierte-sobreincremento-de-la-violencia-domestica-en-el-contexto-de-la-pandemia/

cc) (i) (2) Esta obra está bajo una licencia de Creative Commons ReconocimientoEY No SA NoComercial-Compartirlgual 4.0 Internacional 